\title{
Explaining the Immigration-Partner Violence Link: Attitudes Towards Partner Violence Among Latin-American Immigrants in Spain
}

\author{
E. Gracia ${ }^{*}, 1$, J. Herrero ${ }^{2}$ and M. Lila ${ }^{1}$ \\ ${ }^{I}$ Department of Social Psychology, University of Valencia, Spain \\ ${ }^{2}$ Department of Psychology, University of Oviedo, Spain
}

\begin{abstract}
In order to better understand the relationship between immigration and partner violence, our aim in this study is twofold. First, we compare perceptions and attitudes toward partner violence against women between native-born population and Latin-American immigrants in Spain. And second, we explore correlates of attitudes toward reporting partner violence against women among Latin-American immigrants. Data from the Spanish population was obtained from national representative surveys. Latin-American immigrants were recruited from a community sample of 399 adult participants. Results showed significant differences in attitudes toward intimate partner violence against women between nativeborn and immigrants. Analyses also showed that positive attitudes toward reporting among immigrants were more likely among those respondents who were less tolerant, perceive partner violence against women as a pervasive problem in society, and tend not to blame the victims. Findings are discussed in light of recent literature on the relevance of public attitudes toward intimate partner violence.
\end{abstract}

Keywords: Attitudes, immigration, partner violence, reporting, violence against women.

\section{INTRODUCTION}

There is a wide consensus on the importance of addressing the social conditions that contribute to partner violence against women for effective prevention efforts [1-7]. Among the social factors that influence rates of domestic violence are those that create an acceptable climate for violence $[6,7$, 8-11]. Public attitudes regarding partner violence against women play an important role in shaping the social environment in which the victims are embedded. For example, indifference, passivity, or victim-blaming attitudes contribute to maintaining a climate of social tolerance that not only may reduce inhibitions for perpetrators but also probably makes it more difficult for women to make partner violence visible, choosing not to report or abandon the relationship [12-17]. As Jenkins noted [16], silence remains a prevalent community response to partner violence against women, and those who know about the violence but choose to be silent and passive contribute to "perpetuate a regime of silence, denial, and neglect -a regime in which survivors assume they will not be believed and outsiders continue to disbelieve" $[13$, p. 1060]. Furthermore, attitudes of tolerance and acceptability of partner violence sometimes implicitly condone or even support violence against women $[6,12,13,16]$.

In this paper we explore attitudes toward partner violence against women among a minority group of the Spanish population: Latin-American immigrants. Two related facts motivate this study. First the current growth of the immigrant population in Spain (Latin-American immigrants being one of the largest groups), and second, the fact that, despite being

*Address correspondence to this author at the Department of Social Psychology, Facultad de Psicología, Universidad de Valencia, Avda. Blasco Ibáñez 21, 46010 Valencia, Spain; E-mail: enrique.gracia@uv.es a minority group of the population, there is a disproportionate high incidence of partner violence against women among immigrant population in Spain. In order to better understand the relationship between immigration and partner violence in our cultural context, our aim in this study is twofold. First, we compare attitudes toward partner violence against women between native-born population and Latin-American immigrants. And second, we explore correlates of attitudes toward reporting partner violence against women among LatinAmerican immigrants.

\section{IMMIGRATION AND PARTNER VIOLENCE AGAINST WOMEN IN SPAIN}

Spain is increasingly becoming an immigrant-receiving country with one of the fastest immigrant population growth in western countries. Immigration accounted for a net increase in Spain from 2000 to 2007 of approximately 3 million people. Spain is also one of the main destinations for Latin-American immigration in Europe (in addition of the economic opportunities, there is also the issue of cultural proximity, as we share the same language -except for Brazil). For example, in just one year (2006-2007) the immigrant population increased by $31 \%$, of which $14.3 \%$ was from Latin-American countries. Currently (2007 full year data), immigrant population make up about $10 \%$ of the population in Spain, of which $30.5 \%$ are Latin-American immigrants [18]. Despite being a minority group, partner violence against women among immigrant population is a problem of growing concern in Spain. Data of officially reported partner violence against women cases in Spain shows that about one third of all reported cases were perpetrated by immigrants. Also, nearly $40 \%$ of women victims of fatal partner violence were immigrant women of which $50 \%$ were Latin-American [19]. This data supports findings in other cultural contexts 
according to which partner violence is one of the main forms of victimization suffered by immigrant women [20-25].

In addition to officially reported data, is important to note that in Spain, as in other western countries, most cases of nonfatal partner violence against women are never reported to the authorities. Prevalence data in Spain are similar to that observed in other Western countries. The last National Incidence Survey in Spain [26] estimated that between 4\% and $12.4 \%$ of adult women had been victims of intimate partner violence (depending of the definitions of violence used). In European countries, an analysis of 10 prevalence studies estimated that about $25 \%$ of women have experienced intimate partner violence during their lifetime, and about $6 \%$ to $10 \%$ in a given year $[27,28]$. Despite this high prevalence, in Spain many instances of partner violence against women are seldom reported to the authorities, representing only between $4 \%$ and $11 \%$ of the total estimated cases. For example, $70 \%$ of women victims of fatal partner violence never reported any past incidents to the authorities [19]. Another point is that nobody else did.

\section{THE PRESENT STUDY}

Research conducted mostly in U.S.A revealed that ethnicity and immigrant status are associated with higher level of involvement in partner violence [25, 29-35]. Available data in Spain suggest a similar pattern. Research efforts have been directed to identify the factors that may explain or mediate this relationship. Sociocultural status, acculturation and gender role attitudes [31, 36-39]; the stresses and challenges associated to the immigrant status [23, 40,41]; or women's perceptions and tolerance of partner violence [42-45], have been considered as important factors that may explain the increased risk for intimate partner violence among minority and immigrant groups. Also, it has been suggested that higher levels of involvement by minorities and immigrants in violence are mediated in part by the community context where they live -environments of extreme poverty or highly disadvantaged, segregation, social isolation [46-48]. However, McLoyd, Cauce, Takeuchi, and Wilson noted in their review that controls for income, education, urbanicity, age and number of children, and duration of marriage reduces, but does not eliminate, the relationship [49].

Less attention has been paid, however, to differences in public attitudes toward partner violence between immigrant and native-born populations. In the current study, instead of focusing on attitudes of victims or perpetrators of partner violence, we focus on attitudes of the general public (both immigrants and native-born) toward partner violence against women, a rather neglected research area. In the first part of the study, we will compare perceptions and attitudes regarding partner violence against women between Spanish nativeborn population and Latin-American immigrants living in Spain. Comparisons will be made on a set of perceptions regarding the perceived pervasiveness of partner violence: public exposure to incidents of partner violence (whether respondents know victims), and perceived frequency of partner violence against women in society. Comparisons will also be made on a set of attitudes tapping social acceptability of partner violence against women: tolerance of partner violence, victim-blaming attitudes, and attitudes toward reporting partner violence to the police. Given the high incidence of partner violence among immigrants in Spain, we hypothesise that, compared to native-born population, LatinAmerican immigrants will know more women that are hit by their partners, and will consider it as more common. We also hypothesise that among immigrants there will be a more favourable social climate toward partner violence. That is, compared to native-born population, partner violence will be more tolerated, women will tend to be blamed more for the violence, and positive attitudes toward reporting partner violence to the authorities will be less common among immigrants.

In the second and most central part of the study, we will analyze public willingness to exert informal social control regarding partner violence, by exploring correlates of attitudes toward reporting partner violence against women to the authorities among Latin-American immigrants. A better understanding of the correlates of reporting attitudes and behavior regarding partner violence against women may add relevant knowledge to the literature on the social conditions that contribute to partner violence, as well as the social sources of deterrence and control of domestic violence. As Gelles proposed in his "Exchange/social control theory of family violence" [9], the absence of effective social controls reduce the costs and increase the rewards of being violent in intimate relationships. And reporting incidents of partner violence is a way of exerting social control. However, except for few exceptions (see Gracia \& Herrero [4], for an analysis of correlates of attitudes toward reporting among native-born Spanish population), little research effort has been directed to explore public willingness to act when exposed to partner violence against women. Public attitudes toward reporting partner violence provides an indicator of the social climate regarding partner violence that surrounds victims, and the public willingness to exert social control of domestic violence [5, 9, 50-52]. As Fagan argued [50], the willingness to exert social control among the social networks and communities in which the couples are embedded may play an important role in deterring and preventing partner violence. A social environment (including neighbors, friends, coworkers, or acquaintances) willing to act and to get involved, may act as an inhibiting force for perpetrators, and may reduce inhibitions toward reporting both for witnesses as well as for victims $[9,50,53]$.

In this study we explore the following correlates of attitudes toward reporting partner violence against women (see Gracia \& Herrero [4], for a similar approach): public exposure, perceived frequency, tolerance, and victim-blaming attitudes. Perceptions and attitudes regarding partner violence may be relevant factors in determining attitudes toward reporting partner violence. For example, some research suggests that knowing a victim of partner violence is associated with a negative attitude toward reporting it to the authorities [4]. Perceived frequency of partner violence may also help shape public attitudes toward reporting as it may increase the sense of personal responsibility [6]. Attitudes toward reporting partner violence may also depend on public tolerance of all or only certain types of incidents of partner violence against women. For example, if partner violence against women is considered as such only when it involves extreme, severe or repeated violence, it is more likely that some violence toward women in intimate relationships may be acceptable in certain circumstances $[54,55]$. If some incidents 
of partner violence are perceived as acceptable or not serious enough (e.g., threats, non severe physical aggression) is less likely a positive attitude to intervene. For example, research showed that a higher level of tolerance (i.e., some levels of violence are normal or acceptable) is associated with negative attitudes toward reporting [4]. Victim-blaming attitudes may also influence negatively attitudes toward reporting partner violence. As psychosocial research has showed, being held responsible for their own victimization reduces significantly the chances of help being offered [56- 59].

Finally, we used eight socio-demographic controls (gender, age, marital status, income, education, years of residence in Spain, trust in authorities, and legal status as immigrant) that might be related to both predictors and outcome variables [4, 31, 49, 60, 61].

\section{METHODOLOGY}

\section{Sample}

Two types of data were used in this study. First, we used available data from national representative surveys on intimate partner violence of Spanish population. These data includes a Spanish national survey of 2498 adults 18 years old and over on different issues of domestic violence conducted in 2004 by the Center for Sociological Research. Also, Spanish-related data from the Eurobarometer 51.0 "Europeans and their views on domestic violence against women" was used for this study. It was carried out in 1999 and covered the population of residents 15 years and over in each of the Member States of the European Union (EU) at that time (see Gracia \& Herrero $[4,11]$ for a detailed description of these surveys).

Second, 399 Latin-American immigrants were recruited from two Autonomous Communities in Spain: Asturias and Valencia. Participants were identified following a two-step process. In the first step, researchers contacted nongovernmental organizations and other legally established associations that worked with Latin American immigrants in both Communities. These associations covered a wide range of activities (from legal assistance to spare-time activities) with immigrants. Some of these associations were run by non-immigrant personnel while others were run by immigrants themselves. The main reason to contact these associations was to gain access to a sizable number of eligible participants for the study. In the second step, participants were contacted through these organizations and associations with the aid of the staff personnel, and invited them to participate in the study. Self-administered questionnaires were given to those who agreed to participate in the study with instructions to return them once completed. Questionnaires were administered in Spanish, the mother-language of all participants in the study.

This sample is not representative of Latin American immigrants in Spain since it is almost impossible to create a random probabilistic sample of Latin American immigrants because of the lack of reliable census data on immigration. Estimates of the immigrant population in Spain suggest that at the end of year 2007 almost $10 \%$ of the Spanish population was immigrant. About $25 \%$ of this immigrant popula- tion is Latin-American, although this percentage varies across the nation: Asturias, 43\%; Valencia, 33\%.

\section{Measures}

Personal exposure to partner violence against women. Respondents were asked: "Do you know a case of domestic violence against women?" $(1=n o, 2=y e s)$. Perceived frequency of partner violence against women was measured with the following question: "As far as you know, what is the frequency of domestic violence against women within Spanish families?" The response categories are: $1=$ nonfrequent, 2 = somewhat frequent, 3 = frequent, and $4=$ very frequent. Tolerance of partner violence against women. A question asked individuals: "Under what circumstances do you think a female victim of violence from her partner should report it to the legal authorities?" The response categories are: 1 = as soon as the woman feels she is being threatened by her partner even if there is not physical aggression, 2 = if there is physical aggression though nonsevere, and $3=$ only if severe physical aggression is present. Victim-blaming attitudes. A question asked individuals: A cause of partner violence against women is the provocative behavior of women $(1=$ Yes, $0=$ No).

\section{Dependent Variable}

Attitudes toward reporting partner violence against women was measured with the following question: "What would you do if being at home you hear that a neighbor is beating his wife?" $(0=I$ would not report it to the police, $1=$ I would report it to the police).

\section{Control Variables}

Age (in years). Gender $(1=$ men, $2=$ women $)$. Educational level was coded $1=$ no educational background, $2=$ elementary school, 3 = high school, $4=$ university studies. Marital status was coded $1=$ single, $2=$ married, and $3=$ separated/divorced. Household Income was measured in 12 categories from $1=$ less than 1.800 euros a year, $12=$ more than 120.000 euros a year. Time of residence in Spain was measured in years. Legal status as immigrant was measured asking respondents if they were legally established in the country $(1=y e s, 2=n o)$. We also included an additional control variable by measuring trust in police in order to ascertain if attitudes toward reporting were conditioned by a previous attitude toward police. Trust in police was measured with an item adapted from the European Social Survey [62], "Do you trust the police?" The response categories ranged from 0 (no trust at all) to 10 (complete trust). In Table 1 we present the distribution of sociodemographic and control variables.

\section{RESULTS}

About $40 \%$ of participants were men. Average educational level in the sample was high (the percentage of participants with high school or higher is above $80 \%$ ). Most of participants were married at the time of the study $(52.9 \%)$ and also were legally established in Spain (80.4\%). Mean age was 34 and average household was near the lower end (6,000-12,000 euros/year). The average time of residence in Spain was 5 years. Finally, participants expressed in the average that they trusted the police (6.3 in a $0-10$ scale). 
Table 1. Distribution of Sociodemographic and Control Variables $(\mathbf{N}=399)$

\begin{tabular}{|c|c|}
\hline & Percentages \\
\hline \hline Men & 40.7 \\
\hline Educational level & \\
\hline No educational background & 0.7 \\
\hline Elementary School & 13.9 \\
\hline High school & 58.6 \\
\hline University Studies & 26.8 \\
\hline Marital Status & \\
\hline Single & 34.3 \\
\hline Married & 52.9 \\
\hline Separated/divorced & 12.8 \\
\hline Legal Status as immigrant (Yes) & 80.4 \\
\hline & Average \\
\hline \hline Age & 34.6 \\
\hline Household Income & $6,000-12,000$ euros/year \\
\hline Time of residence in Spain & 5 years \\
\hline Trust in police & \\
\hline
\end{tabular}

Taken as a whole, participants in the study were educated, married, legally established in the country, middle-age and were living for five years in the country. It is important to note that although most participants were legally established and educated, their household income was in the lower-end of the scale.

\section{Perceptions and Attitudes Regarding Partner Violence Against Women Among Native-Born and Latin- American Immigrants}

In the first part of the study we explored if native-born and immigrant participants held different views about intimate partner violence against women and, also, if both groups presented different levels of personal exposure to partner violence against women. To do so, we compared the distribution of responses of the Spanish population (as indicated by published results of national surveys) with the responses of the sample of Latin-American immigrants participating in the study. Table 2 presents the distribution of responses for both native-born and immigrants along with a $\chi 2$-test of their differences.

Results in Table 2 clearly suggest that, in Spain, nativeborn and immigrants held different views on partner violence against women and that they were exposed to partner violence against women to a different degree. Thus, the percentage of immigrants who knew a victim of partner violence against women was more than twice of the Spaniards percentage. Maybe as a consequence, immigrants perceived that partner violence against women is more frequent than Spaniards. Finally, they tolerate partner violence against women to a greater extent, tend to blame the victim of partner violence against women more frequently and would report a known incident of partner violence against women in fewer occasions.

Table 2. Perceptions and Attitudes Regarding Partner Violence against Women among Native-Born Spanish and Latin-American Immigrants in Spain

\begin{tabular}{|l|c|c|c|}
\hline & Native-Born & Immigrants & $\chi^{\mathbf{2}}$ \\
\hline \hline Personal exposure (Yes) & 23.0 & 54.1 & $170.30^{* * *}$ \\
\hline Perceived frequency & & & \\
\hline Very frequent & 16.6 & 55.9 & $306.17^{* * * *}$ \\
\hline Tolerance & & & \\
\hline Threats & 78.5 & 69.3 & $16.01 * * *$ \\
\hline Victim-blaming (Yes) & 39.2 & 56.5 & $41.56^{* * *}$ \\
\hline Would report (Yes) & 75.0 & 63.8 & $21.56^{* * *}$ \\
\hline
\end{tabular}

${ }^{\mathrm{l}}$ Data retrieved from CIS (2004) and European Commission (1999) surveys. $* * * \mathrm{p}<.001$

\section{Correlates of Attitudes Towards Reporting Partner Vio- lence Against Women}

In the second part of the study, we analyzed the correlates of attitudes towards reporting partner violence against women to the authorities. For the analyses, we used multivariate binomial logistic regression for dependent variables with two categories [63]. Noncontinuous predictor variables were modeled as categorical in order to estimate "whether the effect of being in a certain category is statistically significantly different from being in the reference category" $[63$, p. 52]. For assessing model fit we estimated Model $\chi 2$, which is analogous to the multivariate $F$ test for linear regression. If we reject the null hypothesis we can conclude that at least one beta in the model is nonzero [64]. In other words, the information about the independent variables allows us to make better predictions than we could make without them. Analyses were performed using the SPSS 15 software package.

At the bottom of Table 3 we present the results from multivariate multinomial logistic regression analysis. Model $\chi 2$ was highly significant $(\chi 2=66.19, \mathrm{gl}=15, \mathrm{p}<.001)$ (see bottom of Table 3 ), thus rejecting the null hypothesis that the independent variables were not significantly associated with the dependent variable.

The only statistically significant control variable was gender. Being male was associated with a decreased odds of reporting partner violence against women of $65.1 \%$ as compared to women. All of the core variables of the study showed a statistically significant relationship with attitudes toward reporting partner violence against women, except for personal exposure. Regarding those variables with a positive relationship with attitudes towards reporting partner violence against women we found that a one-unit increase in perceived frequency was associated with a $227 \%$ increased odds of reporting partner violence against women. As for the variables negatively related with reporting, we found a $48.4 \%$ decrease of the odds of reporting partner violence against women for those who blamed the victim of partner violence when compared to those who did not blamed the victim. Also, when compared to participants that expressed that a 
woman victim of partner violence should report it to the authorities as soon as there were threats, results indicate a significant decrease in the odds for those who expressed that it should be reported only when there is aggression, although non-severe (80.3\%), and for those who expressed the need of a severe aggression to justify reporting partner violence against women to the authorities (a decrease of 93.8\%).

Table 3. Multivariate Logistic Regression Results for Attitudes Towards Reporting Cases of Domestic Violence against Women ${ }^{1,2}$

\begin{tabular}{|l|c|c|c|c|}
\hline & B & S.E & Sig. & Exp (B) $^{\mathbf{a}}$ \\
\hline \hline Men & -1.052 & .517 & .042 & .349 \\
\hline Frequency & 1.184 & .350 & .001 & 3.269 \\
\hline Victim-blaming (Yes) & -.662 & .229 & .004 & .516 \\
\hline Personal Exposure (Yes) & -.764 & .508 & .132 & .466 \\
\hline Tolerance $^{\mathrm{b}}$ & & & .001 & \\
\hline \multicolumn{1}{|c|}{ Non-severe aggression $_{\text {Only physical aggression }}$} & -1.623 & .525 & .002 & .197 \\
\hline \multicolumn{1}{|c|}{ Ond $^{2}$} & -2.788 & 1.071 & .009 & .062 \\
\hline
\end{tabular}

${ }^{1}$ Model $\chi^{2}(15)=66.19, \mathrm{p}<.001 ;$ Nagelkerke $\mathrm{R}^{2}=.44$.

${ }^{2}$ Non-significant control variables are: age, years of residence in Spain, marital status, educational level, household income, legal status as immigrant, and trust in police.

${ }^{a} \operatorname{Exp}(B)$ is the odds ratio. Significant values greater than 1 indicate a positive attitude towards reporting partner violence against women. ${ }^{b}$ Reference category: threats.

\section{DISCUSSION}

A number of studies have shown higher levels of involvement in partner violence among immigrants. In Spain, where the present study was conducted, data also reveals a disproportionate higher incidence of partner violence against women (both fatal and nonfatal) among immigrant population, in particular from Latin-American countries. In order to better understand the link between immigration and partner violence, in the first part of this study we compared perceptions and attitudes regarding partner violence against women among native-born Spaniards and Latin-American immigrants living in Spain. The second part of the study explored the willingness to exert informal social control among immigrants by exploring different sets of correlates of attitudes toward reporting partner violence against women.

First, results show that the high incidence of partner violence among immigrants is paralleled by their perceptions. Compared to native-born, immigrants report knowing more victims (54.1\% vs 23\%), and perceived partner violence as more frequent in society ("very frequent" $=55.9 \% \mathrm{vs}$ $16.6 \%)$. Results also showed that, compared to native-born respondents, there is a more favorable social climate toward partner violence among Latin-American immigrants. According to our data this social climate of acceptability can be portrayed in terms of greater tolerance of partner violence ("violence from her partner should be report it to the legal authorities as soon as the woman feels she is being threatened by her partner even if there is not physical aggression" $=69 \%$ immigrants agreed $v s 78.5 \%$ native-born), greater tendency to blame the women victim of partner violence for their own victimization (56.5\% vs 39.2\%), and less willingness to exert social control by reporting known cases of partner violence against women to the authorities $(63.8 \% v s$
75\%). These results may help explain the higher rates of partner violence among the Latin-American immigrant population in Spain, and supports the idea that rates of domestic violence are related to the social climate of acceptability and tolerance $[4,6,8-11]$. In this respect, the World Health Organization considered among the larger societal factors that influence rates of violence, those that create an acceptable climate for violence, and those that reduce inhibitions against violence [7]. A social environment that condones or even supports domestic violence makes it more likely for perpetrators to persist in their violent behavior $[6,14,15$, 65]. This view is shared by a number of scholars who believe that without a fundamental change in the social attitudes that perpetuate male violent acts against women, the problem of violence against women will not be solved [3, 10, 11, 13]. As Biden [13] put it "we cannot hope to respond effectively to violence against women unless we confront and condemn the attitudes that nurture the violence" (p. 1060). In this regard, our results also suggest that better targeted education efforts directed to those groups who share views and attitudes of acceptability and tolerance of partner violence are needed for a more effective prevention.

In the second part of the study we explored correlates of attitudes toward reporting partner violence against women to the authorities among Latin-American immigrants. Results from socio-demographic variables analyses showed that women report a more positive attitude toward reporting partner violence than men. This finding is in line with research suggesting that women perceived partner violence as more severe, are less accepting, and feel more personal responsible to act than men, which suggest greater empathy for the victims $[4,66,67]$. None of the other sociodemographic controls explores yielded significant differences.

With respect to the correlates of attitudes toward reporting partner violence against women, except for "personal exposure", all variables examined yielded significance. That is, among Latin-American immigrants, those who perceived partner violence as more frequent in society, are less tolerant, and do not blame the victims, have a more positive attitude toward reporting partner violence against women.

With regard to perceived frequency of partner violence against women in society, we found, as in previous studies with native-born population [4], that this was a significant correlate of positive attitudes toward reporting partner violence. This suggests that greater public recognition of the occurrence of partner violence against women in society favors positive attitudes toward reporting it to the authorities. As Klein et al. argue [6], social and personal accountability to take action against domestic violence comes from believing that the problem is widespread and of sufficient threat to the community fabric that affects one's own life. This also suggests that past and future efforts to increase the social visibility of partner violence against women as a public issue of serious concern have helped and probably will continue to help shape public attitudes, increasing feelings of responsibility [6, 68]. It follows that an important target for public education campaigns is to keep increasing public awareness of the alarming pervasiveness of partner violence against women in our society.

Our findings also showed that a lower level of tolerance was associated with a positive attitude toward reporting. Ac- 
cording to this, for a number of respondents some violence (e.g., threats, non-severe physical aggression) seemed to be tolerated to a higher degree. In line with other studies, this finding suggest that when some violence (less extreme forms) towards women in intimate relationships is perceived as more "tolerable", the chances of others to be sensitive to their needs and receiving help might be significantly reduced $[4,55,69]$. As Gracia and Herrero [11] put it: "clearly, public education efforts that challenge these attitudes of tolerance and transmit the idea of social responsibility concerning issues of domestic violence are necessary. Breaking the climate of social tolerance would increase the costs for perpetrators and contribute to the informal social control of domestic violence against women" (p. 128). In addition to public education efforts directed to the general population, our results suggest that public policies aiming to reduce the tolerance of domestic violence against women among immigrants in general and Latin-American in particular, are clearly needed. These public education efforts need to transmit the idea that all forms of violence are wrong, and must not be accepted under any circumstances.

Victim-blaming attitudes were also associated with attitudes toward reporting partner violence among LatinAmerican immigrants. Respondents that blamed the victims of partner violence tend to report a negative attitude toward reporting. Blaming the victims not only implies tolerance of violence under some circumstances, but also reduces the victims' chances of receiving help. According to social psychological theory, when victims are believed to cause their own troubles or to get what they deserve the chances for the victims of receiving help are significantly reduced [11, 56$59,70]$. These results suggest the need for public education efforts to target prevalent victim blaming attitudes among Latin-American immigrants. Finally, although some research suggests an association between knowing a victim of partner violence and attitudes toward reporting [4], in this study we found that personal exposure to incidents of partner violence was unrelated with attitudes toward reporting.

The study has some potential limitations. First, as already mentioned in the method section, from the three samples used in this study two of them were probabilistic and representative of the Spanish population whereas the sample on Latin-American immigrants was not. In this sense, we should be cautious about the comparisons between native-born and Latin-American immigrants in their respective views on domestic violence since there is not a complete equivalence among the samples used in the study. However, the high prevalence rates of domestic violence among LatinAmerican immigrants observed in Spain suggest that the differences found in our study point to the right direction. Second, measures used in this study are single items, which opens up a number of validity and reliability issues that should be addressed in future research. Third, we can not claim the generalizability of results to Latin-American population in Spain since our study focused in two Communities: Asturias and Valencia. Finally, we can not rule completely out the possibility that some of the immigrants participating in the study were involved in domestic violence themselves (both as aggressors or victims). Had been this case, it is tenable that it had some effect on the relationships found in the study. Research focusing on aggressors could be an interesting counterpart to this study that would allow to explore in depth the role that attitudes toward domestic violence and personal exposure to partner violence against women have in the willingness to intervene and to exert informal social control in our communities and neighborhoods. Future research on this topic should address these potential limitations.

\section{CONCLUSION}

In this study we aimed to better understand the disproportionate higher incidence of partner violence against women among a minority group of the population: Latin-American immigrants. As we hypothesized, Latin-American immigrants not only knew more women victims of partner violence and perceived it as more common compared to nativeborn population, but most importantly, our results confirmed that Latin-American immigrants held a set of attitudes that create an acceptable climate for partner violence against women. Partner violence against women thrives in a social climate of tolerance. Without targeting these attitudes of tolerance and acceptability through education efforts, it will be difficult to reduce the disproportionate high rates of partner violence against women among Latin-American immigrants living in Spain.

\section{ACKNOWLEDGEMENTS}

Support for this research was provided by a grant from the Spanish Ministry of Education and Science (SEJ200608666/PSIC).

\section{REFERENCES}

[1] American Psychological Association Presidential Task Force on Violence and the Family. Report of the American Psychological Association Task Force on Violence and the Family. Washington, DC: 1996.

[2] Gelles RJ. Through a sociological lens: Social structure and family violence. In Gelles RJ, Loseke DR, Eds. Current controversies on family violence. Newbury Park, CA: Sage 1993; pp. 31-46.

[3] Goodman LA, Koss MP, Fitzgerald LF, Russo NF, Keita GP. Male violence against women: Current research and future directions. Am Psychol 1993; 48: 1054-8.

[4] Gracia E, Herrero J. Public attitudes toward reporting partner violence against women and reporting behavior. J Marriage Fam 2006; 68: 759-68.

[5] Gracia E, Herrero J. Perceived neighborhood social disorder and attitudes toward reporting domestic violence against women. J Interpers Violence 2007; 22: 737-52.

[6] Klein E, Campbell J, Soler E, Ghez M. Ending domestic violence: Changing public perceptions/halting the epidemic. Thousand Oaks, CA: Sage 1997.

[7] World Health Organization. World report on violence and health. Geneva, Switzerland: 2002.

[8] Fagan JA. Cessation of family violence: Deterrence and dissuassion. In Tonry M, Ohlin L, Eds. Crime and justice: An annual review of research. Chicago: University of Chicago Press 1989; pp. 377-425.

[9] Gelles RJ. An exchange/social control theory. In Finkelhor D, Gelles RJ, Hotaling GT, Straus MA, Eds. The dark side of families. Thousand Oaks, CA: Sage 1983; pp. 151-65.

[10] Gracia E. Unreported cases of domestic violence against women: Towards an epidemiology of social silence, tolerance, and inhibition. J Epidemiol Community Health 2004; 58: 536-537.

[11] Gracia E, Herrero J. Acceptability of domestic violence against women in the European Union: A multilevel analysis. J Epidemiol Community Health 2006; 60: 123-129.

[12] Bennet L, Williams OJ. Men who batter. In Hampton RL, Ed. Family violence: Prevention and treatment. $2^{\text {nd }}$ ed.. Thousand Oaks, CA: Sage 1999; pp. 227-259.

[13] Biden JR Jr. Violence against women: The congressional response. Am Psychol 1993; 48: 1059-1061.

[14] Fagan, J. Contributions of research to criminal justice policy on wife assault. In Besharov D, Ed. Family violence: Research and 
public policy issues. Washington, DC: American Enterprise Institute Press 1990; pp. 53-81.

[15] Harden BJ, Koblinsky SA. Doble exposure: Children affected by family and community violence. In Hampton RL, Ed. Family violence: Prevention and treatment $2^{\text {nd }}$ ed. Thousand Oaks, CA: Sage 1999; pp. 66-102.

[16] Jenkins P. Threads that link community and family violence: Issues for prevention. In Hampton RL, Jenkins P, Gullotta TP, Eds. Preventing violence in America. London: Sage 1996; pp. 33-52.

[17] Lackey C, Williams KR. Social bonding and the cessation of partner violence across generations. J Marriage Fam 1995; 57: 295305.

[18] Observatorio permanente de la inmigración. Extranjeros con certificado de registro o tarjeta de residencia en vigor a 31 de diciembre de 2007. Madrid: Ministerio de Trabajo y Asuntos Sociales 2008.

[19] Instituto de la Mujer. Denuncias por malos tratos producidas por el cónyuge o análogo. Año 2007. Madrid, Spain: 2008.

[20] Bachman R, Saltzman LE. Violence against women: Estimates from the redesigned survey. NCJ-154348 Special Report. Washington, DC: U.S. Department of Justice, Bureau of Justice Statistics 1995.

[21] Dasgupta SD. Charting the course: An overview of domestic violence in the south Asian community in the United States. J Soc Distress Homeless 2000; 9: 173-185.

[22] Davis RC, Erez E. Immigrant population as victims: Toward a multicultural criminal justice system. Washington, DC: National Institute of Justice 1998.

[23] Hazen AL, Soriano FI. Experiences with intimate partner violence among latina women. Violence Against Women 2007; 13: 562-582.

[24] Morash M, Bui H, Zhang Y, Holtfreter K. Risk factors for abusive relationships: A study of Vietnamese American immigrant women. Violence Against Women 2007; 13: 653-675.

[25] Raj A, Silverman JG. Violence against immigrant women: The roles of culture, context, and legal immigrant status on intimate partner violence. Violence Against Women 2002; 8: 367-398.

[26] Instituto de la Mujer. La violencia contra las mujeres. Resultados de la macroencuesta. II Parte. Madrid, Spain: 2003.

[27] Council of Europe. Recommendation Rec(2002)5 of the Committee of Ministers to member States on the protection of women against violence adopted on 30 April 2002 and Explanatory Memorandum. Strasbourg, France: 2002.

[28] Kury H, Obergfell-Fuchs J, Woessner G. The extent of family violence in Europe. Violence Against Women 2003; 10: 749-769.

[29] Crowell NA, Burgess AW. Understanding violence against women. Washington, DC: National Academy Press 1996.

[30] Hass GA, Dutton MA, Orloff LE. Lifetime prevalence of violence against Latina immigrants: Legal and policy implications. Int Rev Victimology 2000; 7: 93-113.

[31] Kantor GK, Jasinski JL, Aldarondo E. (). Sociocultural status and incidence of marital violence in Hispanic families. Violence Vict 1994; 9: 207- 222

[32] Sorenson SB, Telles CA. Self-reports of spousal violence in a Mexican-American and non-Latino White population. Violence Vict 1991; 6: 3-15.

[33] Straus MA, Gelles RA, Steinmetz SK. Behind closed doors: Violence in the American family. Garden City, NY: Doubleday 1980.

[34] Tran CG, Des Jardins K. Domestic violence in Vietnamese refugee and Korean immigrant communities. In Chin JL, Ed. Relationships among Asian American women. Washington, DC: American Psychological Association 2000; pp. 71-96.

[35] Van Hightower NR, Gorton J, DeMoss CL. Predictive models of domestic violence and fear of intimate partners among migrant and seasonal farm worker women. J Fam Violence 2000; 15: 137-154.

[36] Bhanot S, Senn CY. Attitudes towards violence against women in men of south asian ancestry: Are acculturation and gender role attitudes important factors? J Fam Violence 2007; 22: 25-31.

[37] Jasinski JL. The role of acculturation in wife assault. Hisp J Behav Sci 1998; 20: 175-192.

[38] Perilla JL, Bakeman R, Rorris FH. Culture and domestic violence: The ecology of abused Latinas. Violence Vict 1994; 9: 325-39.

[39] West CM, Kantor GK, Jasinski JL. Sociodemographic predictors and cultural barriers to help-seeking behavior by Latina and Anglo American battered women. Violence Vict 1998; 13: 361-75.

[40] Caetano R, Cunradi CB, Clark CL, Schafer J. Intimate partner violence and drinking patterns among White, Black, and Hispanic couples in the U.S. J Subst Abuse 2000; 11: 123-38.
[41] Rodriguez R. Clinical interventions with battered migrant farm worker women. In Campbell JC, Ed. Empowering survivors of abuse. Thousand Oaks, CA: Sage 1998; pp. 271-279.

[42] Asbury J. Violence in the families of color in the United States. In Hampton R, Gullotta T, Adams G, Potter E, Weissberg R, Eds. Family violence: Prevention and treatment. Newbury Park, CA: Sage 1993; pp. 159-78.

[43] Campbell, DW, Maskai B, Torres S. Water on rock: Changing domestic violence perceptions in the African American, Asian American, and Latino communities. In Klein E, Campbell J, Soler E, Guez M, Eds. Ending domestic violence: Changing public perceptions/halting the epidemic. Thousand Oaks, CA: Sage 1997; pp. 64-87.

[44] Gabler M, Stern SE, Miserandino M. Latin American, Asian, and American cultural differences in perceptions of spousal abuse. Psychol Rep 1998; 83: 587-92.

[45] Gondolf E, Fisher E, McFerron R. Racial differences among shelter residents: A comparison of Anglo, Black, and Hispanic battered women. In Hampton R. Ed. Black family violence: Current research and theory. Lexington, MA: Heath 1991; pp. 103-13.

[46] Benson M, Wooldredge J, Thistlethwaite A, Fox G. The correlation between race and domestic violence is confounded with community context. Soc Probl 2004; 51: 326-42.

[47] Sampson RJ, Lauritsen JL. Violent victimization and offending: Individual-, situational-, and community-level risk factors. In Reiss AJ Jr., Roth J, Eds. Understanding and preventing violence: Social Influences (Vol. 3). Washington, DC: National Academy Press 1994; pp. 1-114.

[48] Wilson WJ. The truly disadvantaged: The inner city, the underclass, and public policy. Chicago: University of Chicago Press 1987.

[49] McLoyd VC, Cauce AM, Takeuchi D, Wilson L. Marital processes and parental socialization in families of color: A decade review of research. J Marriage Fam 2000; 62: 1070-93.

[50] Fagan J. Social structure and spouse assault. In Forst B, Ed. The socio-economics of crime and justice. New York: Sharpe 1993; pp. 209-254.

[51] Gracia E, Herrero J. Perceived neighborhood social disorder and residents' attitudes toward reporting child physical abuse. Child Abuse Negl 2006; 30: 357-365.

[52] Lackey C, Williams KR. Social bonding and the cessation of partner violence across generations. J Marriage Fam 1995; 57: 295 305.

[53] Kelly L. Tensions and possibilities: Enhancing informal responses to domestic violence. In Edleson JL, Eisikovits ZC, Eds. Future interventions with battered women and their families. Thousand Oaks, CA: Sage 1996; pp. 67-86.

[54] Loseke DR. "Violence" is "violence"...or is it? The social construction of "wife abuse" and public policy. In Best J, Ed. Images of issues: Typifying contemporary social problems. New York: de Gruyter 1989; pp. 191-206.

[55] Muehlenhard CL, Kimes LA. The social construction of violence: The case of sexual and domestic violence. Pers Soc Psychol Rev 1999; 3: 234-45.

[56] Lerner MJ. The desire for justice and reactions to victims. In Macaulay J, Berkowitz L, Eds. Altruism and helping behavior New York: Academic Press 1970; pp. 205-29.

[57] Lerner MJ. The belief in a just world: A fundamental delusion. New York: Plenum 1980.

[58] Weiner B. A cognitive (attribution)-emotion-action model of motivated behavior: an analysis of judgments of help giving. J Pers Soc Psychol 1980; 39: 186-200.

[59] Weiner B. Judgments of responsibility: A foundation for a theory of social conduct. New York: Guildford 1995.

[60] Stowell JI, Martinez R Jr. Comparing the context of immigrant homicides in Miami: Haitians, Jamaicans, and Mariels. Aggression Violent Behav 2007; 12: 564-581.

[61] West CM, Kantor GK, Jasinski JL. Sociodemographic predictors and cultural barriers to help-seeking behavior by Latina and Anglo American battered women. Violence Vict 1998; 13: 361-375.

[62] European Social Survey [on line] 2008 Feb 20. Available from: http://www.europeansocialsurvey.org/

[63] Menard S. Applied logistic regression analysis. Series: Quantitative applications in the social sciences. Thousand Oaks, CA: Sage 1995

[64] DeMaris A. A tutorial in logistic regresión. J Marriage Fam 1995; 57: $956-968$ 
[65] Bennet L, Williams OJ. Men who batter. In Hampton RL, Ed. Family violence: Prevention and treatment. $2^{\text {nd }}$ ed. Thousand Oaks, CA: Sage 1999; pp. 227-259.

[66] Gracia E, García F, Lila M. Police involvement in cases of intimate partner violence against women: The influence of perceived severity and personal responsibility. Violence Against Women 2008; 14.

[67] West A, Wandrei ML. Intimate partner violence: A model for predicting interventions by informal helpers. J Interpers Violence 2002; 17: 972-986.
[68] Straus MA, Gelles RJ. Societal change and change in family violence from 1974 to 1985 as revealed by two national surveys. J Marriage Fam 1986; 48: 465-479.

[69] Loseke DR, Gelles RJ. Conclusion: Social problems, social policy, and controversies on family violence. In Gelles RJ, Loseke DR, Eds. Current controversies on family violence. Newbury Park, CA: Sage 1993; pp. 357-366.

[70] Batson CD. Altruism and prosocial behavior. In Gilbert DT, Fiske S, Lindzey G, Eds. The handbook of social psychology. New York: McGraw-Hill 1998; pp. 282-316.

(C) Gracia et al.; Licensee Bentham Open.

This is an open access article distributed under the terms of the Creative Commons Attribution License (http://creativecommons.org/licenses/by/2.5/), which permits unrestrictive use, distribution, and reproduction in any medium, provided the original work is properly cited. 